\title{
Panorama sobre el dengue en los Estados miembros del Mercosur (1991-2015)
}

\author{
Viviana Masciadri ${ }^{1}$
}

Forma de citar

Masciadri V. Panorama sobre el dengue en los Estados miembros del Mercosur (1991-2015). Rev Panam Salud Publica. 2019;43:e11. https://doi.org/10.26633/RPSP.2019.11

RESUMEN Objetivo. En la actualidad, el virus del dengue constituye un fenómeno endémico que azota la región del Mercosur. El objetivo de esta investigación es elaborar un diagnóstico sobre la situación epidemiológica causada por el dengue en los Estados miembros y asociados del Mercosur.

Métodos. Se utilizaron datos estadísticos — tasas de morbilidad por dengue estimadas para el período 1980-2015, y especialmente del período 1991-2015-, junto con un corpus de leyes sanitarias, comerciales, laudos, informes ejecutivos y bibliografía específica.

Resultados. Se observó que, a excepción de Chile y Uruguay, los países asociados o miembros del Mercosur — principalmente Brasil, que exhibe la mayor incidencia mundial de casos de dengue- necesitan identificar los factores que favorecen el aumento de la propagación de la endemia.

Conclusiones. Este breve panorama sobre los Estados miembros del Mercosur en el período 1991-2015 se fundamenta en datos macroestructurales que ponderan y, al mismo tiempo, representan el sumatorio de los cuatro elementos establecidos por la OMS y la OPS para el control del dengue: la voluntad política de los Gobiernos, la coordinación intersectorial, la participación de la comunidad y el fortalecimiento de las leyes sanitarias nacionales.

Palabras clave Salud pública; dengue; incidencia; neumáticos usados; Mercosur.

La elaboración de un diagnóstico sobre la situación sanitaria derivada del dengue es crucial por razones de salud pública en todo el mundo, ya que más de 2500 millones de personas —es decir, $40 \%$ de la población mundial- viven en zonas donde las probabilidades de contraer dengue son elevadas. La Organización Mundial de la Salud (OMS) ha

\footnotetext{
Consejo de Investigaciones Científicas y Técnicas, Universidad de Buenos Aires, Facultad de Filosofía y Letras, Instituto Interdisciplinario de Estudios de Género, Ciudad de Buenos Aires, Argentina. La correspondencia se debe dirigir a Viviana Masciadri, viv2041@gmail.com
}

determinado que el dengue es endémico - es decir, que existe circulación del virus durante todo el año- en América, el sudeste asiático, el Pacífico occidental, África y el Mediterráneo oriental (1) .

La Región de las Américas se caracteriza por presentar un alto grado de urbanización, a tal punto que alberga cinco de las treinta megalópolis del planeta: dos están en Brasil (posición 4 y 19) y las restantes, en México, Argentina y Perú (posiciones 6, 13 y 30, respectivamente). Considerando que el mosquito se ha adaptado a los entornos urbanos, el riesgo de contraer la enfermedad se potencia $(2,3)$. Además, las grandes urbes son el centro de las actividades productivas y gubernamentales donde el debilitamiento de los sistemas de salud pública como resultado de las privatizaciones desmedidas y la falta de programas sostenibles han favorecido la propagación del dengue al sur del Río Bravo hasta convertirse en una enfermedad endémica en toda la región, salvo en Chile y Uruguay. En contextos de escasa planificación sanitaria, el aumento del tránsito de personas y mercancías que conlleva la globalización favorece la propagación del vector en todo el planeta (4).

Según datos de la OMS (5), la media anual de casos notificados de dengue y 
dengue grave en el período 1955-1959 fue de 908 en el mundo y ascendió a 15497 casos entre 1960 y 1969. En el período 1970-1979, se notificó un promedio anual de 122174 casos, mientras que en el período 1980-1989 se informaron 295554 casos. Entre 1990 y 1999, el promedio anual notificado fue de 479 848 casos y en el período 2000-2007, de 925896 casos. Luego, la tendencia aumentó: se notificaron 1279668 casos en 2008, 1451083 en 2009 y 2204516 en 2010.

El Mercado Común del Sur (Mercosur) representa un proceso basado en dos elementos esenciales de toda política de integración regional: el intercambio comercial de mercancías y la circulación de personas (6-7). En este sentido, resulta sustancial identificar y abordar los aspectos sanitarios que supone este proceso en pos de contrarrestar los factores que han favorecido la propagación del dengue en la región. A tales efectos, se requiere la intervención coordinada de los Estados, sobre todo en las zonas fronterizas, portuarias y aeroportuarias.

Este espacio de integración regional está conformado por un grupo de países donde el riesgo de contraer dengue es elevado debido a dos factores: 1) el elevado volumen poblacional que, según estimaciones de la Organización Panamericana de la Salud (OPS), asciende a $303167 \quad 749$ personas —207 847528 $(68,6 \%)$ residen en Brasil; 43416755 (14,3\%), en Argentina; 31108083 (10,3\%), en Venezuela; 10724705 (3,5\%), en Bolivia; 6639123 (2,2\%), en Paraguay, y 3431 $555(1,1 \%)$ en Uruguay- y 2) el alto grado de urbanización - en países miembros $(85,5 \%)$ y en asociados $(76,6 \%)$ guarismos correspondientes a 2015 .

El objetivo de esta investigación es elaborar un diagnóstico sobre la situación epidemiológica causada por el dengue en los Estados miembros y asociados del Mercosur.

\section{MATERIALES Y MÉTODOS}

Mediante la interpretación de datos de vigilancia epidemiológica publicados por la OPS en la Plataforma de Información en Salud de las Américas (PLISA) sobre Dengue, y recopilados por el Programa Regional de Dengue denominado Estrategia de Gestión Integrada para el control y prevención del dengue en las Américas (EGI-Dengue), se analizó la evolución de las tasas de morbilidad por dengue
- prestando especial atención al período 1991-2015- en los Estados miembros y asociados del Mercosur en los últimos treinta y cinco años (1980-2015).

En los estudios comparativos de series temporales es importante que los insumos (datos) se estandaricen bajo un criterio estadístico común que permita calcular la incidencia de dengue por cien mil habitantes. Es decir, la razón metodológica explica la elección de la fuente que permite conocer la evolución de la incidencia de dengue en el período 19802015 y reconsiderar, a la luz de los datos, algunos de los aspectos propios de las políticas de salud en el contexto del Mercosur.

Mediante la información estadística publicada en PLISA, y a partir de la selección de los temas referidos al dengue, se conformó una serie temporal de datos relacionados con el número de casos de dengue, la población y la incidencia de dengue por cien mil habitantes a escala nacional para el conjunto de los países del Mercosur. A fin de evaluar la calidad de los datos, se recalculó la incidencia para cada país y, por último, se obtuvo la tasa de morbilidad por dengue de los Estados miembros y asociados del Mercosur en el período 1980-2015. Cabe destacar que el denominador de la tasa es congruente con estimaciones procedentes de los sistemas estadísticos nacionales y con estimaciones de la Comisión Económica para América Latina y el Caribe (CEPAL).

Por otra parte, para analizar los aspectos sanitarios relativos a la evaluación de la coordinación intersectorial y legislativa sobre el dengue en la región del Mercosur, se conformó un corpus de leyes sanitarias, comerciales, laudos, informes ejecutivos, declaraciones y demás documentos procedentes de los sitios oficiales de organismos internacionales - Mercado Común del Sur (Mercosur), Asociación Latinoamericana de Integración (ALADI), Organización Mundial del Comercio (OMC) - y de los Ministerios de Salud tanto de los Estados miembros (Brasil, Venezuela, Paraguay, Bolivia, Argentina, Uruguay) como de los Estados asociados (Colombia, Ecuador, Perú, Guyana, Surinam, Chile).

\section{RESULTADOS}

Según datos de la OMS, Brasil ocupa el primer puesto entre los treinta países del mundo con mayor número de casos notificados de dengue. Otros países donde el dengue es endémico son Venezuela, Colombia, Bolivia, Perú, Paraguay, Ecuador y Argentina, que ocupan los puestos $5,8,13,18,19,27$ y 30 , respectivamente.

$\mathrm{Al}$ analizar la evolución de las tasas de morbilidad por dengue en los países del Mercosur, se observan incrementos irregulares, pero constantes. En términos comparativos, los Estados miembros del Mercosur tienen mayores dificultades para controlar el dengue, tal como indican las tasas de los Estados asociados.

En 1991 - los albores del Mercosur-, si bien Brasil era el único Estado miembro donde se habían registrado casos de dengue (63,6 por cien mil), los problemas de salud vinculados con la endemia del dengue también existían en Bolivia (1392,9 por cien mil), Colombia (43,3 por cien mil), Venezuela (32,3 por cien mil), Perú (3,2 por cien mil) y Ecuador ( 0,9 por cien mil).

Hacia 2015, en cambio, las tasas más elevadas de morbilidad por dengue en la región provenían de Paraguay (1034,1 por cien mil), Brasil (793,4 por cien mil), Bolivia $(275,4$ por cien mil), Ecuador (263,2 por cien mil), Colombia (200 por cien mil), Venezuela (174,1 por cien mil) y Perú (114,2 por cien mil), mientras que, en otros países, la incidencia seguía siendo baja o moderada, como en Guyana (50,6 por cien mil), Argentina (11 por cien mil) y Surinam (2,8 por cien mil). Por último, como ya se ha comentado, Uruguay $(0,4$ por cien mil) y Chile $(0,2$ por cien mil) mostraron ser los únicos dos países de la región donde el dengue no era -ni es- endémico.

Dicho de otro modo, durante los primeros quince años del siglo XXI, los Estados del Mercosur no desarrollaron estrategias de control comercial conjuntas para limitar la propagación continua de la endemia a raíz de la situación epidemiológica registrada en la región. En las figuras 1 y 2 se muestra la evolución de las tasas de morbilidad por dengue en los Estados miembros y asociados. Las líneas de tendencia respectivas y los coeficientes de correlación $\left(\mathrm{r}^{2}\right)$ expresan la asociación entre las tasas de morbilidad por dengue y el tiempo ( $t$, en años): la asociación es fuerte en el primer grupo de países y débil en el segundo.

Cabe destacar que las tasas provinciales de dengue, al ser un indicador agregado, invisibilizan la situación de las zonas fronterizas, donde la exposición al riesgo de contagio es mayor a causa de la circulación turística y comercial, tal como 
FIGURA 1. Tasas de incidencia de dengue (por cien mil habitantes) en los Estados miembros del Mercosur, 1980-2015

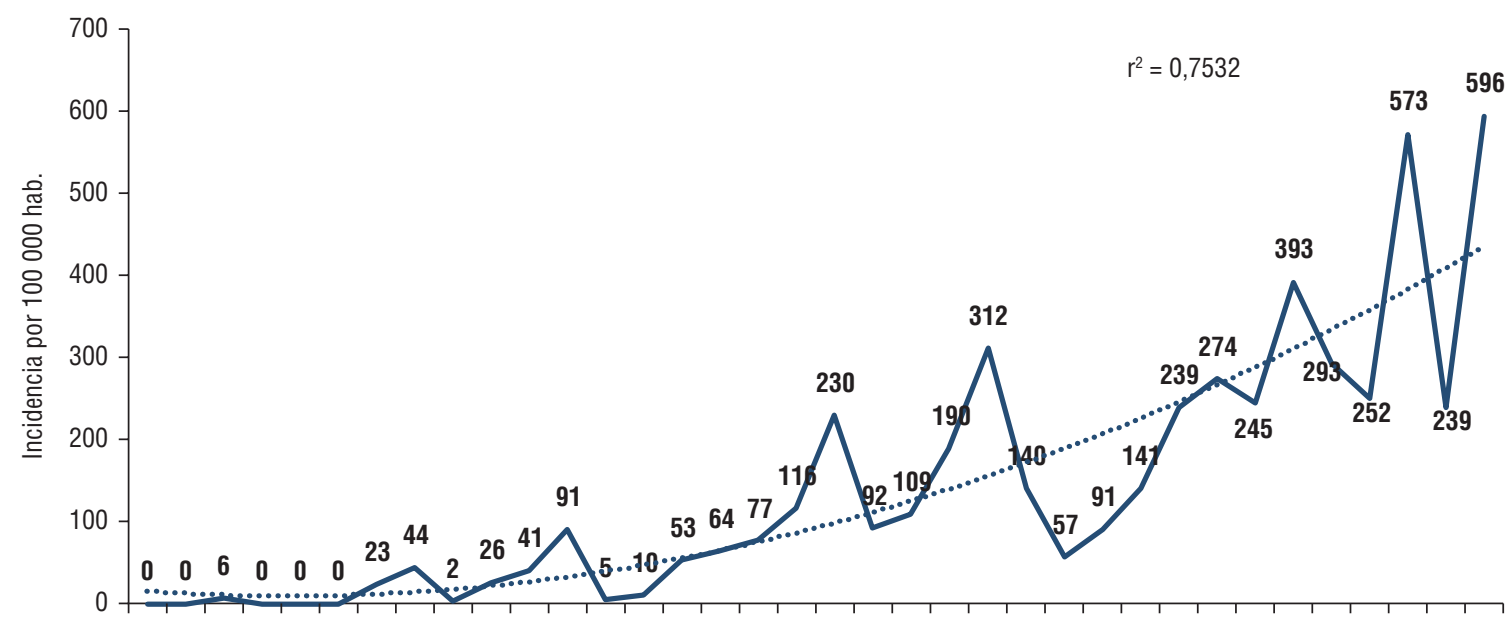

。

Años

— Miembros ...... Polinómica (Miembros)

Fuente: elaboración propia a partir de datos de la OPS, la OMS y la PLISA: http://www.paho.org/data/index.php/es/temas/indicadores-dengue/dengue-nacional/240dengue-incidencia.html?showall=1\&limitstart=

Nota: $\mathrm{r}^{2}$ expresa la asociación entre las tasas de morbilidad por dengue y el tiempo (t, en años).

FIGURA 2. Tasas de incidencia de dengue (por cien mil habitantes) en los Estados asociados del Mercosur, $1980-2015$

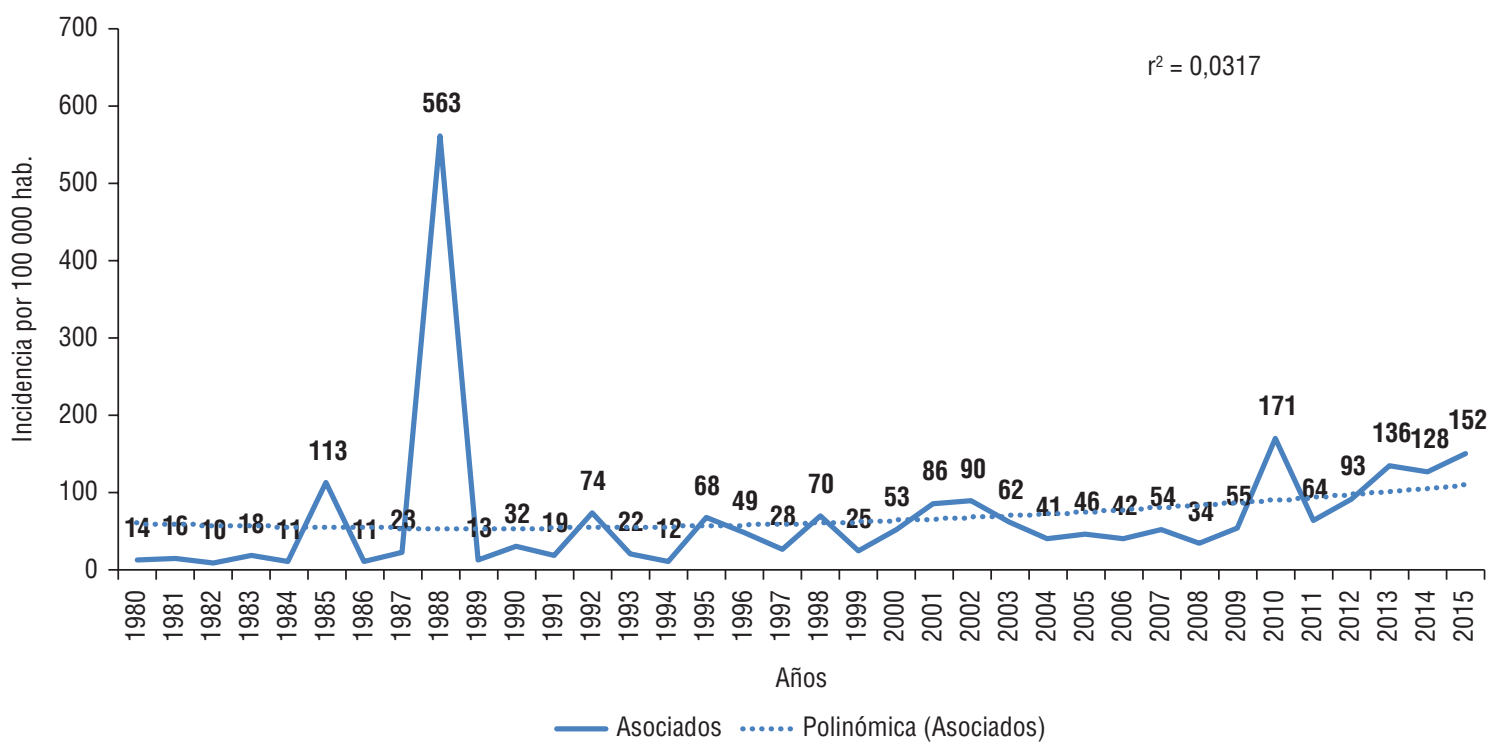

Fuente: elaboración propia a partir de datos de la OPS, la OMS y la PLISA: http://www.paho.org/data/index.php/es/temas/indicadores-dengue/dengue-nacional/240dengue-incidencia.html?showall=1\&limitstart=

Nota: $\mathrm{r}^{2}$ expresa la asociación entre las tasas de morbilidad por dengue y el tiempo (t, en años).

sucede en la provincia de Misiones, en la ciudad de Buenos Aires y en el conurbano bonaerense, que, además, presentan corredores terrestres, fluviales, marítimos, aéreos y ferroviarios múltiples y de envergadura.

En efecto, desde la semana epidemiológica (SE) SE1 a la SE28 (del 3 al 9 de enero hasta el 10-16 de julio) de 2016, la tasa nacional de Argentina ascendió a 95 por cien mil, mientras que la de Misiones fue de 1784 por cien mil (8). La información departamental indica que, desde la SE1 a la SE16 (3-9 de enero al 17-23 de abril), la tasa de Misiones fue de 1692 por cien mil, mientras que en Eldorado dicha cifra ascendió a 4712 por cien mil, y, en Posadas, fue de 4144 por cien mil (9).

Con todo, en 2015, la provincia de Misiones sancionó el Plan Provincial 2016-2018 de Prevención y Control del Dengue, Fiebre Amarilla Urbana y Chikungunya (10), aunque no logró contener la epidemia. 


\section{Dilema subyacente al intercambio de neumáticos usados en el Mercosur}

Tal como se describe más arriba, el mencionado proceso de integración económica y regional comenzó en 1991 y estuvo formado inicialmente por los Estados miembros de Argentina, Brasil, Paraguay y Uruguay, a los que, más tarde, se sumaron Venezuela y Bolivia. En esa etapa, se forjaron otras vías de intercambios bilaterales entre los Estados miembros, los asociados y terceros —Chile, Colombia, Ecuador, Perú; las repúblicas de Sudáfrica, India, Egipto, Pakistán, Singapur, Marruecos, Turquía, Corea, Siria, Túnez y Líbano; los Estados de Israel y Palestina; la Federación de Rusia y el Reino Hachemita de Jordaniao agrupaciones de países regionales y extrazona -México y Cuba por la Asociación Latinoamericana de Integración, y Estados miembros del Consejo de Cooperación de los Estados Árabes del Golfo, la Unión Aduanera de África del Sur y la Comunidad Europea (11) -

Entre esos países subyace el dilema relativo al intercambio de neumáticos usados y reconstruidos (reacondicionados) (12), con excepción de los neumáticos montados en llanta. En el Informe del Órgano de Apelación de la Organización Mundial del Comercio (OMC) se reconoce que cuando los neumáticos se convierten en desechos, su acumulación pone en riesgo la salud y la vida tanto de las personas como de los animales, así como la preservación de la flora. En los seres humanos, los riesgos para la vida y la salud incluyen la transmisión del dengue, la fiebre amarilla, el paludismo, el zika y el chikungunya por mosquitos que utilizan los neumáticos como criaderos (13-14).

En efecto, existen controversias acerca de las prohibiciones comerciales de dicho producto entre países del bloque Uruguay, Argentina y Brasil- o entre países extrazona, como sucedió con la Unión Europea, que demandó a Brasil por discriminación ante la $\mathrm{OMC}$, un proceso que se resolvió a favor del demandante (15-17).

De la lectura del Acuerdo sobre transporte internacional terrestre no se desprenden medidas fitosanitarias (18-20), lo que, además de revelar la existencia de barreras en la traslación de las prácticas sobre estrategias de empoderamiento para la prevención del dengue, incide en su dispersión mundial (21).
Un caso singular es el de Chile, donde se prohíbe la importación de neumáticos usados por razones de salud pública $y$, de ese modo, se evita la introducción del mosquito perteneciente a la especie $A e$ des albopictus, el transmisor de enfermedades epidémicas como el dengue y la fiebre amarilla. Cabe recordar que dicha especie es un vector de transmisión de origen asiático que se ha propagado a Canadá, Norteamérica y a más de veinticinco países europeos a través del comercio de neumáticos usados y del bambú de la suerte (22-23).

En cuanto a la circulación de personas, las autoridades de salud del Mercosur emitieron una declaración el 3 de febrero de 2016 sobre la grave situación de la epidemia y la necesidad de establecer un sistema de información ciudadana de fácil acceso en puertos, aeropuertos y pasos de frontera, con medidas de prevención y control, a pesar de que la $D e-$ claración de Salud del viajero en el Mercosur ya se había emitido algunos años antes (24). Es decir, si bien se conocen las estrategias preventivas que se han de adoptar, no se dan las condiciones necesarias para erradicar el vector $y$, por lo tanto, resulta imprescindible aplicar controles intensivos para evitar epidemias (25-26).

Hay que destacar que las tasas de incidencia por dengue indican que, salvo Chile y Uruguay, el resto de los países asociados o miembros del Mercosur necesitan visibilizar la situación asociada con la tendencia ascendente de la endemia. En Brasil, el reto es aún mayor: siendo el país que exhibe la mayor incidencia mundial de casos de dengue, el 11 de noviembre de 2015 se publicó la portaria $n^{\circ}$ 1813, una ordenanza a través de la cual se declaró la Emergência em Saúde Pública de Importância Nacional y se coordinaron las acciones pertinentes a escala nacional, provincial y municipal.

Es importante advertir que la política sanitaria de Brasil involucra a varios sectores estatales —incluidas las Fuerzas Armadas de ese país (27-28)—, aunque desatiende tanto a los sectores del transporte de pasajeros y de productos en cualquiera de sus vías de ingreso, como al sector responsable de comercializar neumáticos usados. Esto obedece a que Brasil aún no ha articulado los aspectos relativos a la coordinación intersectorial $\mathrm{y}$ al fortalecimiento de las leyes sanitarias que incluyen prohibiciones, como se hizo en Chile mediante la Resolución 1108 o Plan Nacional para Evitar la Introducción del Mosquito Aedes Albopictus o en Argentina con la Ley 25.626/2002 (29-30), que, si bien prohíbe la importación de neumáticos usados, deja abierto el intercambio de ese producto en cantidades iguales sin contemplar en su letra una medida sanitaria de conjunto.

En síntesis, el Plan Estratégico de Acción Social del Mercosur (31-32) tendría que acentuar la prohibición comercial de neumáticos usados en los países miembros, asociados, terceros o agrupaciones de países extrazona. Además, con este Plan se deberían adecuar los controles fitosanitarios teniendo especial cuidado en el control de los productos importados que contengan agua y provengan de algún país donde el dengue es endémico.

No hay que minimizar las limitaciones de este estudio, que aborda uno de los determinantes sociales y comerciales vinculados con el aumento de la incidencia de dengue en la población del Mercosur. Otros determinantes sobre higiene ambiental aluden a carencias de agua potable y a la insuficiente e ineficaz recolección de residuos domiciliarios. Entre los factores de riesgo que no se han abordado en este estudio se encuentran las variaciones en el registro de temperaturas y precipitaciones extremas y la abundancia de vectores (33). Como el proceso de urbanización del Mercosur se ha llevado a cabo sin planificación previa, para lograr disminuir el riesgo diferencial de transmisión del virus dengue en las ciudades, la presente investigación debería complementarse con estudios dirigidos a conocer la estacionalidad de la distribución espacial de la actividad de ovipostura de Aedes, que, por otra parte, también es urbano - en Buenos Aires, la mayor actividad de Aedes aegypti tiene lugar durante los meses cálidos, en barrios de viviendas bajas y de menor aglomeración de edificios altos- (34). Otra limitación de la investigación estriba en que analiza indirectamente la relación entre la comercialización de neumáticos usados y la tasa de morbilidad por dengue, aunque existen pruebas empíricas suficientes que justifican el procedimiento adoptado.

\section{DISCUSIÓN}

Esta investigación diagnostica la situación epidemiológica del dengue en los Estados miembros y asociados del Mercosur. El panorama descrito se fundamenta en datos macroestructurales que ponderan y, al mismo tiempo, representan 
el sumatorio de los cuatro elementos establecidos por la OMS y la OPS para el control del dengue: la voluntad política de los Gobiernos, la coordinación intersectorial, la participación de la comunidad y el fortalecimiento de las leyes sanitarias nacionales. Dicho sumatorio, que se sintetiza en la magnitud de la tasa de incidencia del dengue en los Estados miembros y asociados del Mercosur, refleja, en definitiva y en este contexto, la desarticulación entre el sector sanitario, el comercial y el de transporte y pone más de relieve todavía la situación de Chile, donde tempranamente se advirtió el problema sanitario a escala mundial vinculado con el destino final de los desechos de consumo, como sucede con los neumáticos usados y reconstruidos (reacondicionados). de salud en las Américas. Rev Panam Salud Publica. 2006;19(3):143-5.

2. United Nations, Department of Economic and Social Affairs, Population Division World. Urbanization Prospects. The 2014 Revision, Highlights (ST/ESA/ SER.A/352). New York: UN; 2014. Disponible en: https://esa.un.org/unpd/ wup/publications/files/wup2014-highlights.pdf Acceso el 15 de agosto de 2018.

3. Comisión Económica para América Latina y el Caribe. Población, territorio y desarrollo sostenible. Santiago de Chile: CEPAL; 2012. Disponible en: https://www.cepal. org / sites / default / files / events / files/2012-96-poblacion-web.pdf Acceso el 15 de agosto de 2018.

4. Bhatt S, Gething P, Brady O, Messina J, Farlow A, Moyes C, et al. The global distribution and burden of dengue. Nature. 2013;496(7446):504-7. Disponible en: http:/ / nrs.harvard.edu/urn-3:HUL. InstRepos:11878919 Acceso el 24 de octubre de 2017.

5. World Health Organization. Global strategy for dengue prevention and control 2012-2020. Geneve: WHO; 2012.

6. Beck U. ¿Qué es la globalización? Falacias del globalismo, respuestas a la globalización. Barcelona: Paidós; 1998.

7. Vázquez López, R. Empresas transnacionales y evolución de la integración comercial en América Latina: 1995-2008. Intl J Latin America Studies. 2011;1(1):65-93.

8. Ministerio de Salud. Boletín Integrado de Vigilancia, $N^{\circ}$ 309, SE 19, mayo de 2016.

9. Ministerio de Salud. Boletín Integrado de Vigilancia, N 320, SE 30, julio de 2016.

10. Presidencia de la Nación, Ministerio de Justicia y Derechos Humanos. Salud Pública. Plan provincial 2016-2018 de prevención y control del dengue. Decreto 521/15. Misiones: Boletín Oficial, 14 de agosto de 2015. Buenos Aires: Sistema Argentino de Información Jurídica; 2015.
En suma, para contrarrestar esta situación puntual que ha favorecido la propagación del dengue se requiere que cada Estado -principalmente los que integran el Mercosur- fortalezca las acciones intersectoriales con urgencia.

Agradecimientos. La autora expresa su agradecimiento a la Universidad Nacional Tres de Febrero y a la Universidad de Buenos Aires, a la revisora de estilo Best Version y a la Revista Panamericana de Salud Pública por el apoyo que le han prestado en la elaboración de la versión final de este manuscrito.

Financiación. Este estudio ha recibido financiación del Ministerio de Ciencia, Tecnología e Innovación Productiva y del Consejo Nacional de Investigaciones Científicas y Técnicas en el marco del Proyecto: Dato/nodato: sistemas estadísticos nacionales y derechos humanos universales en países miembros y asociados del Mercosur. Diagnóstico y aportes metodológicos a través del fondo con Código $10020170100725 \mathrm{CO}$.

Conflictos de interés. La autora declara no tener conflictos de interés.

Declaración. Las opiniones expresadas en este manuscrito son responsabilidad de los autores y no reflejan necesariamente los criterios ni la política de la RPSP/ PAJPH y/o de la OPS.

\section{REFERENCIAS}

Disponible en: http://www.saij.gob.ar/ salud-publica-plan-provincial-2016-2018prevencion-control-dengue-salud-publica-plan-provincial-2016-2018-prevencioncontrol-dengue-nv12448-2015-06-26/ 123456789-0abc-844-21ti-lpssedadevon Acceso el 25 de agosto de 2018.

11. Secretaría del Mercosur. Mercosur: estructuras y agendas. Montevideo: Secretaría del Mercosur; 2015. Disponible en: http:// www.Mercosur.int/innovaportal/file / 7338/1/Mercosur_academico_final_es_ web.pdf Acceso el 16 de agosto de 2017.

12. Presidencia de la Nación, Ministerio de Justicia y Derechos Humanos. Ley 26.329. Sancionada: noviembre 28 de 2007. Buenos Aires: Ministerio de Justicia y Derechos Humanos; 2007. Disponible en: http:// servicios.infoleg.gob.ar/infolegInternet/ anexos/135000-139999/136124/norma. $\mathrm{htm}$ Acceso el 12 de agosto de 2018.

13. Organización Mundial del Comercio. Brasil - Medidas que afectan a las importaciones de neumáticos recauchutados. Informe del Órgano de Apelación, WT/ DS332/AB/R., 3 de diciembre de 2007. Ginebra: OMC; 2007. Disponible en: https://www.wto.org/spanish/tratop_s/ dispu_s/332abr_s.doc Acceso el 12 de agosto de 2017.

14. Espinal M. Chikunguña: primera arbovirosis emergente en el siglo XXI en las Américas. Rev Panam Salud Publica. 2017;41:e108.

15. Mercosur. Laudo del tribunal permanente de revisión constituido para entender en la solicitud de pronunciamiento sobre exceso en la aplicación de medidas compensatorias. "Controversia entre Uruguay y Argentina sobre prohibición de importación de neumáticos remoldeados procedentes de Uruguay". Laudo arbitral, 2007. Asunción: Mercosur; 2007. Disponible en: https://betaweb. Mercosur.int/laudos/ Acceso el 16 de agosto de 2017.
16. Mercosur. Tribunal arbitral controversia entre la República Oriental del Uruguay y la República Argentina "Prohibición de importación de neumáticos remoldeados". Laudo arbitral, 2005. Montevideo: Mercosur; 2005. Disponible en: https:// betaweb.Mercosur.int/laudos/. Acceso el 16 de agosto de 2017.

17. Mercosur. Laudo VI del tribunal arbitral ad hoc del Mercosur relativo a la controversia entre la República Oriental del Uruguay y la República Federativa del Brasil sobre "Prohibición de Importación de Neumáticos Remoldeados (Remolded) procedentes de Uruguay". Laudo arbitral, 2002. Montevideo: Mercosur; 2002. Disponible en: http://www.Mercosur. int/msweb/portal\%20intermediario/es/ controversias/arquivos/VI\%20LAUDO. pdf Acceso el 16 de agosto de 2017.

18. Asociación Latinoamericana de Integración. XVIII Reunión de la Comisión de Seguimiento del Acuerdo de Alcance Parcial sobre Transporte Internacional Terrestre (Comisión del artículo 16). Montevideo, 28-30 junio de 2017. Montevideo: ALADI; 2017. Disponible en: http://www.aladi.org Acceso el 11 de agosto de 2017.

19. Asociación Latinoamericana de Integración. Diagnóstico del transporte internacional y su infraestructura en América del Sur (DITIAS): informe ejecutivo, septiembre, 2000. Montevideo: ALADI; 2000. Disponible en: http:// www.aladi.org Acceso el 11 de agosto de 2017.

20. Mercosur. Seguro de responsabilidad civil del propietario y/o conductor de vehículos terrestres no matriculados en el país de ingreso. MERCOSUR/GMC/Res, $\mathrm{N}^{\circ}$ 37/92, VII GMC, Brasilia, 1992. Montevideo: Mercosur; 1992. Disponible en: http://www.Mercosur.int/msweb/ portal\% 20 intermediario/ Normas/normas_web/Resoluciones / 
P T / GMC_RES_1992_037_P T _ SeguoResponsaCivil.PDF Acceso el 11 de agosto de 2017.

21. Pérez D, Castro M, Álvarez A, Sánchez L, Toledo M, Matos D, et al. Traslación a la práctica de estrategias de empoderamiento en la prevención del dengue. Rev Panam Salud Publica. 2016;39(2):93-100.

22. Ministerio de Salud. Resolución 1108. Aprueba el Plan Nacional para Evitar la Introducción del Mosquito Aedes Albopictus. Santiago de Chile: Biblioteca del Congreso de Chile; 1994. Disponible en: https:// www.leychile.cl/N?i=39519\&f $=1994-09$ $15 \& p=$ Acceso el 12 de agosto de 2017.

23. Organización Mundial de la Salud. Dengue y dengue grave. Ginebra: OMS; 2017. Disponible en: http://www.who. int/mediacentre/factsheets/fs 117 /es / Acceso el 12 de agosto de 2018.

24. Mercosur. Declaración de Salud del viajero en el Mercosur. MERCOSUR/GMS/ Res. No. 09/03, LGMC, 2003. Montevideo: Mercosur; 2003. Disponible en: http:// www.Mercosur.int/innovaportal/v/599 / 2 /innova.front/resoluciones-2003 Acceso el 16 de agosto de 2018.

25. Ministerio de Salud Pública y Bienestar Social. Plan Entidades y organismos de la función pública, libres de vectores del dengue, zika y chikungunya. Asunción: Ministerio de Salud Pública y Bienestar Social; 2015. Disponible en: http:/ / portal. mspbs.gov.py/promociondelasalud/wpcontent/uploads/2016/06/1.-Plan-MS-libre-de-vectores.pdf Acceso el 13 de agosto de 2017.

26. Mercosur. Declaración de las ministras y ministros de salud del Mercosur y Estados asociados ante la grave situación epidemiológica determinada por enfermedades transmitidas por el Aedes
Aegypti: Dengue, Chikungunya y Zika. Montevideo: Mercosur; 2016. Disponible en: http://www.Mercosur.int/innovapor$\mathrm{tal} /$ file/7452/1/rms_2016_acta01-ext_ ane06_es_declaracion.pdf Acceso el 16 de agosto de 2017.

27. Ministerio da Saúde, Secretaría de Vigilância em Saúde, Departamento de Vigilância Epidemiológica. Nota informativa No. 01. Emergência de Saúde Pública de Importância Nacional (ESPIN). Brasilia: Ministerio da Saúde; 2015. Disponible en: http:/ / combateaedes.saude.gov.br/es / sala-nacional-de-coordinacion-y-control Acceso el 13 de agosto de 2017.

28. Sala Nacional Coordenação e Controle para o Enfrentamento à Microcefalia. Diretriz SNCC No. 2. Apoio das Forças Armadas. Protocolo de Ações entre Ministério da Integração Nacional, Ministério da Defesa e o Ministério da Saúde. Brasilia: Sala Nacional Coordenação e Controle; 2016. Disponible en: http://combateaedes.saude. gov.br/es/sala-nacional-de-coordinacion-y-control Acceso el 13 de agosto de 2017.

29. Organización Mundial del Comercio. Examen de las Políticas Comerciales. Informe de la Secretaría: CHILE. RESTRICTED WT/TPR/S/220. Ginebra: OMC; 2009. Disponible en: https:// www.wto.org/spanish/tratop_s/tpr_s/ s220-03_s.doc Acceso el 18 de agosto de 2017.

30. Presidencia de la Nación, Ministerio de Justicia y Derechos Humanos. Ley 25.626. Prohíbase la importación de determinadas mercancías incluidas en la Nomenclatura Común del Mercosur e individualizadas y clasificadas en el Sistema Armonizado de Designación y Codificación de Mercancías, 2002.
Boletín Oficial de la República Argentina. Buenos Aires: Ministerio de Salud; 2002. Disponible en: http://servicios.infoleg. gob.ar/infolegInternet/anexos/7500079999/76688/norma.htm Acceso el 12 de agosto de 2017.

31. Instituto Social del Mercosur. Evaluación de avances en la implementación del Plan Estratégico de Acción Social (PEAS). Asunción: Instituto Social del Mercosur; 2017. Disponible en: http://peas.isMercosur.org/es/portada/ Acceso el 12 de agosto de 2018.

32. Secretaría del Mercosur. II Reunión extraordinaria de Ministros de Salud. Mercosur/ RMS/ACTA No. 1/16. Montevideo: Secretaría del Mercosur; 2016. Disponible en: http://www.Mercosur.int/innovapor$\mathrm{tal} /$ file/7452/1/rms_2016_acta01-ext_ es.pdf Acceso el 16 de agosto de 2017.

33. Organización Mundial de la Salud. Proyecto de respuesta mundial para el control de vectores 2017-2030. Ginebra: OMS; 2017. Disponible en: http://www. who.int/malaria/areas/vector_control/ Draft-WHO-GVCR-2017-2030-esp.pdf Acceso el 24 de octubre de 2017.

34. Carbajo A, Gómez S, Curto S, Schweigmann N. Variación espacio-temporal del riesgo de transmisión de dengue en la Ciudad de Buenos Aires. Medicina (Buenos Aires). 2004;64(3):231-4.

Manuscrito recibido el 6 de junio de 2018. Aceptado para publicación, tras revisión, el 7 de septiembre de 2018 .
ABSTRACT

\section{Overview of dengue in the MERCOSUR Member States, 1991-2015}

Keywords
Objective. Dengue virus is an endemic now ravaging the MERCOSUR region. The objective of this research is to assess the epidemiological situation caused by dengue in the MERCOSUR Member States and Associate States.

Methods. Statistical data were used (estimated dengue morbidity rates for the period 1980-2015, with particular focus on 1991-2015), together with a corpus of health legislation, commercial law, arbitration awards, executive reports, and subject-specific literature.

Results. It was found that, with the exception of Chile and Uruguay, MERCOSUR members and associate countries (in particular, Brazil, which has the highest incidence of dengue cases in the world) need to identify the factors that favor the increasing spread of this endemic disease.

Conclusions. This brief overview of the MERCOSUR Member States in the period 1991-2015 is based on a consideration of macrostructural data that represent the sum of the four elements established by WHO and PAHO for dengue control: the political will of governments, intersectoral coordination, community participation, and the strengthening of national health legislation.

Public health; dengue; incidence; used tires; Mercosur. 
RESUMO Objetivo. O vírus da dengue é atualmente um fenômeno endêmico que assola a região do Mercosul. O objetivo desta pesquisa foi fazer um diagnóstico da situação epidemiológica da dengue nos Estados Membros e Estados Associados do Mercosul.

Panorama da dengue nos Estados Membros do Mercosul (1991-2015)

Métodos. O estudo se baseou em dados estatísticos (taxas de morbidade pela dengue estimadas para o período 1980-2015 e, em particular, para o período 1991-2015) e em um corpus de legislação de saúde, legislação comercial, laudos, relatórios executivos e bibliografia específica.

Resultados. À exceção do Chile e Uruguai, os países associados ou membros do Mercosul, sobretudo o Brasil que tem a maior incidência mundial de dengue, precisam identificar os fatores que favorecem o aumento da propagação da endemia.

Conclusões. Este breve panorama da dengue nos Estados Membros do Mercosul no período 1991-2015 está fundamentado em dados macroestruturais que ponderam e, ao mesmo tempo, representam o somatório dos quatro componentes estabelecidos pela OMS e OPAS para o controle da dengue: vontade política por parte dos governos, coordenação intersetorial, participação da comunidade e fortalecimento da legislação nacional de saúde.

Palavras-chave Saúde pública; dengue; incidência; pneus usados; Mercosul. 